\title{
Virtual Manufacturing concepts reducing the Flow Time in Aircraft Manufacturing
}

\author{
Sujit Kumar Jha \\ Engineering Department, Ibra College of Technology, Ibra, Sultanate of Oman \\ skj828@gmail.com
}

\begin{abstract}
The high cost and long lead times of traditional manufacturing makes it difficult for manufactures to efficiently meet eternally changing market demands. In order to determine the manufacturability of the component and low cost production of aircraft manufacturing, Digital Virtual Manufacturing plays a vital role. By the advancement in technologies like Virtual Manufacturing tools used through Product Lifecycle Management (PLM), are competent to access and reuse the best practices, as well as evaluate 3-D manufacturing scenarios. By implementing advance 3-D CAD systems with the CNC machines enables the success of the determinate assembly approach to significantly reduce the lead time aircraft manufacturing. This paper encompasses the virtual manufacturing concept to enable complex manufacturing set-up analysis, exchanging expertise at collaborative work. Virtual Manufacturing is using the manufacturing knowledge at PLM environment for defining the assembly process of an aircraft parts.
\end{abstract}

Index Terms- Virtual Manufacturing, PLM, Collaborative Manufacturing, Assembly Process, Aircraft Structural Parts.

\section{INTRODUCTION}

After globalisation enterprises are facing the challenges arising from continuous innovations, global collaborations, and complex risk management. Logical resources in the form of product and process data must be accessible to anyone in the collaborative chain. To address these issues, Product Lifecycle Management (PLM) has worked as a business approach assimilating people, processes, business systems and information to manage the entire life cycle of a product across the enterprises. As the life span of an aircraft is over 30 years, opportunities abound for the application of PLM in aviation industry. Most of aircraft manufacturing companies encounter the challenge of balancing the optimization of design time with product delivery constraints for shorter the product lead time.

Manufacturing systems and processes are being combined to reduce costs and increase company profitability by simulation technology, computer hardware, and operating systems. One of the most important developments in this regard is called "Virtual Manufacturing", which involves the simulation of products, performance, mechanical functionality and the process involved in its fabrication [1,2]. Virtual Manufacturing is an integrated set of tools that identify steps necessary to manufacture a product, analysis those steps for precision and then produce machine and work instructions for manufacturing the product. Virtual Manufacturing works with product definition data to support part and assembly planning, process design, visualization, simulation and other analyses to digitally plan, validate and optimize manufacturing process. This can shorten time to production, dramatically reduce the need for rework and improve labour utilization and efficiencies.

This paper covers the manufacture of the airframe and mechanical systems, and aircraft assembly. Engine components design and manufacture using advanced technology to assembly line. During 1919 to 1939, there are many changes in design and material of the component has taken place for the improvements of the size and power of the aircraft. Aluminium alloy is the raw material used for making fuselage and wing panels. For aircraft performance requirements and the availability of new materials have resulted in the extensive use of plastics and reinforced plastics (composites). Aircraft structured design is a subset of structural design, which must be designed with care because human life often depends on their performance. 
Some guideline has been given by some researchers based on the concept of design $[3,4]$ for manufacturing and assembly of aircrafts to orient the engineers during the aircraft developing phase for better evolution of manufacturing processes, assembly and maintenance. The guideline helps to improve the easy manufacturing of parts with low costs, and high quality.

\subsection{Virtual Manufacturing Definition}

Virtual Manufacturing (VM) is defined as an aggregation of computer-based information that provides a representation of the properties and behaviours of an actualized product [3]. Virtual Manufacturing is an important area inside the assembly and production process, which evaluate the best work strategy and simulate it by computational modelling of the aircraft's parts and showing the assembly process with its different parameters and specifications. In addition, virtual manufacturing reduces the cost of tooling as well as wastage of materials and also eliminates the need for multiple physical prototypes.

Virtual Manufacturing provides manufacturers with the confidence of knowing that they can deliver quality products to market, on time and within budget. Small improvements in manufacturing have dramatic and profound effects in terms of cost and quality, and it not only happens to the beginning of the life of the product but during its service life [5 - 7]. The VM has been successfully used in different industries. Boeing used virtual manufacturing concept in the development and production of Boeing 777 airplane. Virtual Manufacturing is nothing but an integrated, synthetic manufacturing environment exercised to enhance all levels of decision and control.

There are three paradigms have been proposed for VM in [8]:

1) Design-Centred VM: It will provide an environment for designers to design products and evaluate the manufacturability and affordability of products. It also provides Integrated Product and Process Design (IPPD) to allow simulation of many manufacturing alternatives for the creation of prototypes in the computer.

2) Production-Centred VM: It uses the simulation capability to develop model for manufacturing processes with the purpose of finding inexpensive many processing alternatives.

3) Control-Centred VM: It provides the capability for seamless simulation the actual production to evaluate new or revised product designs with respect to shop floor activities.

\subsection{Advantages of Virtual Manufacturing}

Virtual Manufacturing will reduce time-to-market, reduce the number of physical prototype models and improved quality of the products in design phase as well as optimize the design of product and processes for specific goals. VM will give following advantages[8].

1. Quality: It can be improved by the application of high quality tools and work instructions for production system.

2. Shorter cycle time: by directly going to the production without false start.

3. Producibility: By coordinating with product design, optimization of the design of manufacturing system can be possible and manufacturing system can produce first component trouble-free with high quality.

4. Flexibility: provide product changeovers rapidly, mix production of different products.

5. Responsiveness: respond to customers about delivery schedule with improved accuracy and timeless.

6. Customer relations: improved participation of customers and suppliers in the integrated product process development process. 
Virtual Manufacturing concept implemented in aerospace industry as design and development tools like Finite Element Analysis (FEA) to design and optimize parts by reducing the weight of frames by integral construction, 3D-kinematics simulation to program automatic riveting machines to support complex assembly (Grieves, 2005) [9]. Some researchers [10, 11] have developed a framework based on lean and virtual manufacturing for automatic production of aircraft by using some set of guideline during design phase implemented to engineers at shop floor for reducing flow time at the work center. The success of digital manufacturing implementation is in the arena using advanced computer aided methods that enable manufacturing engineers to operate more directly in assembly planning and concurrent engineering design to improve the efficiency of workers at shop floor [12].

\subsection{Overview of PLM}

Product lifecycle management (PLM) concept arises from two sources. One is enterprise management, which comprises with Material Resource Planning (MRP), Enterprise Resource Planning (ERP), Customer Relationship Management (CRM), and Supply Chain Management (SCM). The other source of PLM is the management of product information during the total lifecycle of the product [13]. In this context, collaboration among virtual enterprises is facilitated by integrating the system of Computer aided Design and Manufacturing (CAD/CAM) and Product Data Management (PDM) systems [14]. From the early 1980s CAD systems play a major role in design and enabled designers to create geometric models of the product more easily than on paper, which can be easily manipulated and reused. With time, the technologies getting advanced, so the kind of information created by Computer-Aided Design, Manufacturing and Engineering (CAD/CAM/CAE) tools threatened to get out of control. As a result, Product Data Management (PDM) systems emerged in the 1980s [10].

Product Lifecycle Management (PLM) concept arises in the 1990s with the goal of moving outside the engineering aspects of an enterprise. PLM can manage information throughout all the stages of a product's lifecycle such as design, manufacturing, marketing, sales and after sales service. As such, ERP, CRM and SCM are integral parts of PLM [14]. During product's lifecycle a large amount of data is generated, which includes CAD data, specifications, quality documents, bill of materials, engineering simulations, etc., that can be shared throughout the extended enterprise [13]. Product definition includes information about how the product is designed, manufactured, operated or used, serviced, and then disposed. All these data can be updated throughout a product's lifecycle [10].

\subsection{Advantages of PLM}

There are many benefits build up from the adoption of PLM, which are followings [10, 13]:

- Delivers more innovative products and services in a shorter time

- Shorten time-to-market

- Establishes a more comprehensive and collaborative relationship with customers, suppliers, and business partners

- Improves communication among departments

With the above advantages of PLM, it is used in the automotive and aerospace industry, followed by the machinery industry [11]. Several vendors, including SAP, IBM, Dassault Systems, and UGS offer PLM solutions to industries. Even though PLM is intended to manage product information throughout the entire lifecycle of a product, an international study revealed that the acceptance of PLM is still mainly limited to product design [11].

\subsection{Application of PLM in the Aircraft Industry}


The application of PLM in the aerospace industry is due to the long lifecycles of their products, more complexity of the products and have nearly no possibility of physical prototyping [11]. IBM-Dassault's PLM Solution, ENOVIA VPM, enabled Dassault Aviation and its 27 partners in North America and Europe to collaboratively design the Falcon 7X business jet. By this it was possible to assemble the aircraft within 7 months instead the usual 16 for comparable aircraft [12].

UGS PLM solution's was deployed in the development of the Boeing 7X7 series of commercial aircraft and the F-35 Joint Strike Fighter (JSF). A Lockheed Martin-led coalition of military aircraft manufacturers and suppliers around the world designed as many as 5000 aircraft using Teamcenter ${ }^{\mathrm{TM}}$ with just three design variants to satisfy the operational needs of the USAF and RAF at the lowest cost of sustainment for a cycle time reduction and anticipates the manufacturing time to be reduced by 66\% [15]. Pratt \& Whitney Canada (P\&WC) has implemented Digital Manufacturing solutions from IBM and Dassault Systems solution to develop aircraft engines to reduced time to market, improved collaboration with partners and saved millions of dollars per year.

Virtual Manufacturing in PLM environment will reduce the inventory, optimize the plant layouts, improve labour utilization, lower production costs and increase production throughput. In a collaborative work environment allowing the company with Virtual Manufacturing as part of PLM approach to improve the followings:

- Translation of design data to manufacturing

- Process planning

- Production operations planning and machining process planning

- Assembly definition and sequencing

- Quality measurement and manufacturing documentation, shop floor instruction and collaboration.

\section{ANALYSIS OF LAYOUT PLANNING AND MANUFACTURING PROCESSES}

The preliminary work consisted in subdividing and grouping the required steps for the assembly into five different workstations: riveting, drilling, de-burring, fixturing and assembly. After that, for each station were defined resources, processes and knowledge using the collaborative work of experts consulted, as well as the previous experiences of the members are utilized The next step was to propose different layouts to arrange the different workstations, considering the work sequence, the timings, the material flows and the value-adding processes. For this task, the PLM digital tools were significantly useful since some of the modules are designed to perform these specific activities, sharing automatically knowledge and information.

\subsection{Materials used Aircraft}

Aluminium alloy is the raw material used for making fuselage and wing panels. The alloys used are over $90 \%$ aluminium, with varying levels of other metals such as copper, zinc and magnesium which improve certain mechanical properties. High tensile steels were used to manufacture aircraft skins during the 1920s and 1930s but were soon replaced by aluminium alloys. Fasteners and fittings are still made from steel. Nickel and titanium alloys also have widespread applications in aircraft engines and for structures where temperature or material compatibility requirements preclude the use of aluminium. Copper, brass and other specialist alloys are used in mechanical and hydraulic systems.

Higher aircraft performance requirements and the availability of new materials have resulted in the extensive use of plastics and reinforced plastics (composites) since the 1970s. The plastics used are usually quite inert, insoluble materials and include acrylics, polyesters, phenolics and epoxy resins. Fibreglass has been used for the reinforced of plastics since the 1950s. More 
recently, carbon and aromatic polyamide fibres and carbon reinforced material such as Kevlar have replaced fibreglass because of their increased tensile strength per unit weight.

\subsection{Manufacturing Processes}

Aircraft structured design is a subset of structural design in general, including ships, land vehicles, bridges, towers and buildings. All structures must be designed with care because human life often depends on their performance. Aircraft structures are designed with proper attention to weight and strength. From 1920s, metal began to be used for aircraft structures. A metal wing is a box structures with the skin comprising the top and bottom, with front and back formed by I-beams called spars.

\subsubsection{Material Forming Operation}

Metal components are usually produced from sheet, tube or bar materials by cutting, machining or forming process. Electrochemical machining, recently introduced for removing materials by anodic dissolution. Heat treatment and annealing processes has been carried out on steel and aluminium alloys to alter the physical properties of the material.

\subsubsection{Manufacturing Composite Materials}

Thermoplastics and thermosetting resin reinforced with fibrous materials are increasingly used in the manufacture of aircraft owing to very high strength to weight ratio. Originally, fibreglass was used with components formed by injection moulding or, more commonly, by contact moulding, where a mould is repeatedly coated with layers of glass fibres and a fast curing polyester resin. In modern manufacturing processes, the fibres and combined to form a tape, the sheets of tape are cut to the desired shape and stacked in a specified orientation, and the resultant laminate is cured in an oven. By forming the composites in the desired shape no working of the materials is required and machining is kept to a minimum. Due to the superior strength and anisotropic stiffness properties of composite materials, airframe weight can be significantly reduced.

\subsubsection{Surface Coating and Cleaning Treatments}

A wide range of coatings are treatments are used in the production of aircraft. Coatings used to prevent from corrosion. Case hardening on steel to impart hard surface layer to improves wear resistance. Acid pickling is used to remove oxide and heat treatment scale from ferrous and non-ferrous metals. Anodising is provided on aluminium or titanium from exposure to atmosphere provides good corrosion resistance and excellent bond for paints and adhesives.

\subsubsection{Electroplating}

Metallic coatings are often applied to metals or other conductive surfaces by electroplating in order to modify surface characteristics such as corrosion resistance, lubricity and wear resistance. Electroplating involves immersing the components in a series of baths to deposit elemental metal. Several metals are used as surface coatings, including cadmium, copper, chromium, nickel and silver.

\subsubsection{Painting}

In the painting process, various paints, enamels and lacquers may be applied, depending on the final finish required. Paints applied using a conventional spray gun, an airless spray gun or a pressurised roller. 


\section{ASSEMBLY OF AIRCRAFT}

Aircraft are made from thousands of structural parts, some as small as playing card, others as large as $30 \times 6 \mathrm{~m}$. All of them are assembled by placing them in dedicated fixtures, matching drilling holes using drill bushings in the fixtures, and then installing the fasteners. Earlier to the 1930s, assembly was carried out using standard joinery techniques. From 1930 to1960, aircraft parts were made of aluminium alloys, joined together by rivets and fasteners, with high tensile steel used for rolled strip spars and end fittings. Since 1960, machined plates of wrought aluminium alloy with bonded reinforced plastics have been used more. This has reduced the number of assembled parts and fasteners and has led to an increasing use of adhesives and sealants during the assembly process.

In the competitive environment, companies have to reduce the cost of manufacturing the aircraft by incorporation of intelligence and automation in the aircraft manufacturing process from manufacture of individual components to final assembly. Traditionally, the most of the assembly operations were manually and therefore more costly as during assembly all individual parts and components need to be properly installed by large team of factory workers.

\subsection{Drivers for use of determinate assembly}

Customers need aircraft, which is more efficient and carry more load than before. In order to meet the above demands and standards, aircraft designers have turned to advanced new tools and methods to evaluate their designs and willingly communicate part geometry to manufacturers. The introduction of computational tools such as Finite Element Analysis (FEA) and Intelligent Computer Aided Design (ICAD) has improved the optimization of design and allows modification of part designs to a level which was not done until recently [16].

The production ramp up rates must meet new more aggressive targets to satisfy market demands. To meet the market demands, precision tooling and assembly equipment are used to fasten or bond together the myriads of parts, which make up the aircraft frame. In order to improve the production rates, it is obligatory for the assembly equipment to be geared up for production as soon as the aircraft components are ready for assembly.

Many researchers have been detailed described about Determinate Assembly [17, 18], which is a term used to describe the practice of designing parts, which fit together at a pre-defined interface, and do not require setting gauges or other complex measurements and adjustments. It is part of more general practice of "Design for Manufacture and Assembly" (DFMA). The prospective advantage of determinate assembly is a reduction in tooling, which thereby reduces both cost and lead-time. Elham et al., [19] have discussed the quasi-analytical method for the estimation of aircraft wing weight which is sufficient to resist the applied loads and further validated using data of various airplanes of different size, category and manufacturer. The designer can assess the effect of different airfoils, different structural layouts and materials. The four major shops within the manufacturing sequence are:
1) Body structures,
2) Wing structures,
3) Join \& Installations and Final Assembly, and 4) Field Operations.

\subsection{Engine Components}

Nowadays composite materials are being used in many non-rotating engine components such as exhaust flaps, fan stator vanes, ducts, inlet plenums, fairings and nose cones. Some of rotating components such as propellers and turbo-fan blades are also using an increasing amount of composite materials. Liquid Composites Moulding (LCM) is used for the production of parts for aircraft engine using resin injection or infusion methods of composite parts fabrication well suited to manufacture complex-shaped details repeatedly to tight dimensional tolerances. Lin et al., [20] have developed an integrated model for cost estimation of rotor blade at the conceptual 
design stage. The model describes the automated estimating process for designing to manufacturing cost of composite rotor blade.

\subsection{Airframe Components}

Due to the highly complex geometrical shapes and the development of advanced materials means the engineer has to look for alternative ways to manufacture these parts. Processes like super plastic forming, hot forming, stretch forming or rubber pad forming are often used to fulfil these requirements. Aircraft structural design must be designed with proper care for the safety of human life often depends on their performance. Aircraft structures are designed with particular attention to weight, for obvious reasons. A metal wing is a box structure with the skins comprising the top and bottom, with front and back formed by I-beams called spars. During turbulence, upper and lower skins can experience both tension and compression. This box structure is able to support the moments and by the elimination of the struts and wires it is possible to reduced air drag that aircraft were able to fly twice as fast as before with the same engine.

Aircraft structures can be made of carbon fibre epoxy composites, which is extremely strong and light. Composite parts are made in layers with proper attention of bonding between the layers. Ultrasonic inspection is used to find any flaws in between layers and skin, and increasingly they can be repaired even in thermo sets. During uncured state, epoxy is sticky, soft, and pliable, where as in its cured state it is hard and rigid. Curing involves heating the epoxy until a chemical reaction begins which provides additional heat and converts the epoxy into its final physical and chemical form. One of the other important advantages of composites is that they can be assembled into large structures by bonding rather than riveting.

The assembly sequence for the subassemblies of the wing is plus chords, pivot rib, and forward and aft spars. The skin and each stringer are joined to the plus chord with multiple fasteners. The assembly sequence is as: the aft skin is placed in the fixture, spacers are placed along its upper edge and the forward skin is placed on those spacers, stringers are placed on the fixture and the assembler drills holes for tack fastening the skin, stringers, and plus chord together. Once the FTB, FTE, and ribs have been placed in the fixture and joined, the wing skin subassemblies are installed onto those parts. There are engineering drawing for all the elements used for assembly the wing. Figure 1 shows the all fabrication processes of horizontal stabilizer.

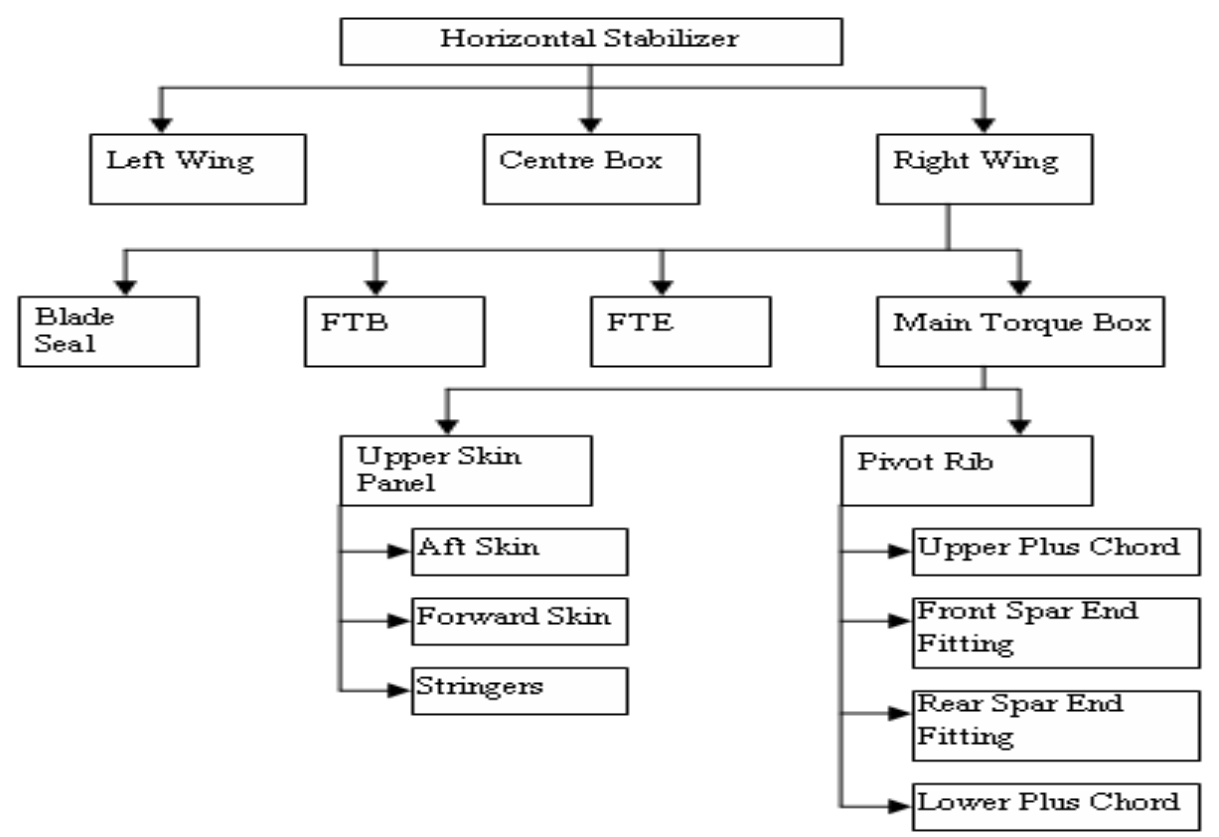

Figure 1 Shows the fabrication process for the parts of the horizontal stabilizer wing. 
The parts of the horizontal stabilizer is a scaled-down version of the wing and has all the same structural parts include upper skin, lower skin, ribs, stringers, spars, and plus chords. These elements form the main torque box, a beam structure that supports the structural loads on the wing. The plus chords are splice elements that connect the wing to the aircraft fuselage. On the aircraft, the leading edge assembly is called the forward torque box (FTB) while the trailing edge segment of interest is called the fixed trailing edge (FTE). Figure 2 shows the connection of spars, skins, and ribs in main torque box to bears the load.

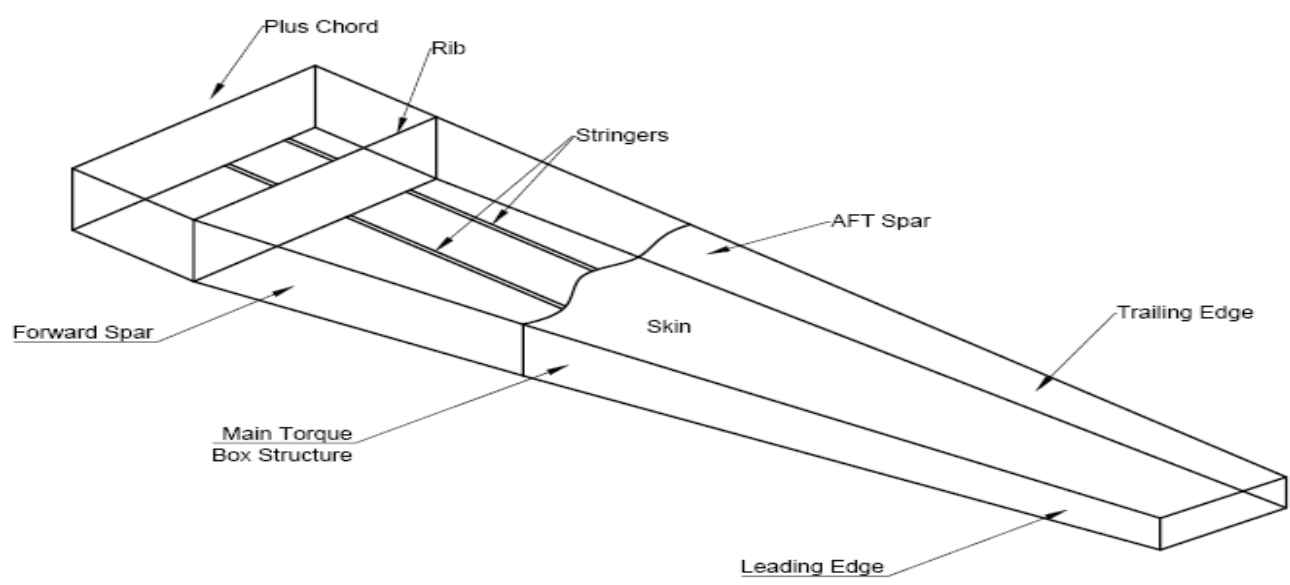

Figure 2 Shows the Main Torque Box structures to bears the loads of the wings.

The assembly sequence to builds fully constrained subassemblies and makes all the incoming mates for each part before any of the contacts are made [21]. This sequence is:

- Place aft skin in assembly support

- Place splice stringer on aft skin, aligning the hole on the aft skin with the hole on the splice stringer and insert a temporary fastener through this hole.

- Place the forward skin on the support; aligning its aft inboard hole with exposed the hole on the splice stringer.

- Insert a temporary fastener through this hole.

- Place the plus chord on the assembly support and align its aft hole with the aft inboard on the aft skin.

- Insert a temporary fastener through this hole.

- Align the forward hole in the plus chord with the forward inboard slot on the forward skin, and insert a temporary fastener through this hole.

- Transport this tacked subassembly to the drill-rivet machine and insert permanent fasteners.

Figure 3 shows all the assembly steps of the horizontal stabilizer for building wing.

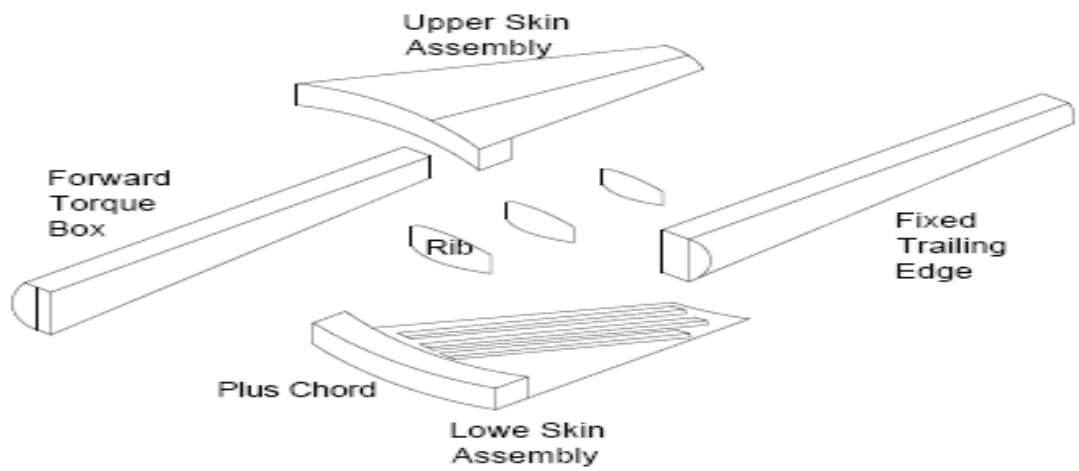

Figure 3 Shows the assembly sequence of the Horizontal Stabilizer. 
The final assembly is the assembly of the skin subassembly to the subassemblies comprising the ribs, the FTB, and the FTE. To complete the assembly of wings and fuselage structures, people must drill hole and insert each fastener individually, debarring when necessary. All assemblies operations of aircraft can be done fastly, using simulation method in virtual manufacturing environment.

\section{RESULTS AND DISCUSSIONS}

The concept of Virtual Manufacturing can be applied to aerospace industry in FEA for optimize the integral parts weight by integral construction and its design, in 3D-kinematics simulation which support during complex assembly and service tasks. The geometry of airplane is modelled in computer-aided 3D interactive application (CATIA) which links the design and virtual manufacturing processes and store all data in a software for product data management. The production cycle time of an airplane is the sum of manufacturing flow time for all work centers to finish the assigned tasks. The flow time for a work center influenced by the crew size and manufacturing work statement, which details the exact tasks and the sequences in which manner tasks should be performed at the work center. The flow time at the work center can be reduced by minimizing the crew size or by selecting optimal crew size, which is the number of workers involved per job. The assembly of an airplane involves a series of manufacturing processes done at many work centers concurrently. In virtual manufacturing environment, the manufacturing flow time can be reduced by planning of airplane manufacturing by considering the delivery schedule, generate a process plan for the sequence of tasks to be done, by monitoring the progress at each work center and compared with the delivery plan. The flow time at each work center can be reduced by above planning, which finally minimize the cost associated with the flow time like inventory carrying cost and variable tooling cost that is the procurement and maintenance of production equipment and tools for the manufacturing process. In virtual manufacturing environment waste can be minimized and smooth flow of components and materials can be achieved by rearranging the equipment and workstations.

\section{CONCLUSIONS}

In a highly competitive marketplace, companies are also challenged to further reduce time-tomarket, while boosting product quality across variable volumes and maximize their returns on investments. By implementing PLM approach to the entire design-manufacture-market strategy allows companies to reduce waste in materials, resources and time and offers a solution to the quality, cost and time pressures of the market. Dassault Systems DELMIA software suite offers a complete solution to the "manufacturing ready" challenge in a PLM enabled environment for manufacturing. As a key component of Dassault Systems V5 PLM portfolio, with CATIA, ENVOIA, and SIMULA brands, DELMIA solutions deliver a digital manufacturing process environment to optimize production system before moving to physical implementation, at the convenience of a desktop.

\section{REFERENCES}

[1] Qin, S., Harrison, R., and Wright,D. "Development of a novel 3D simulation modelling system for distributed manufacturing", Computers in Industry, 54 (1): 69-81, 2004.

[2] Deviprasad, T., Kesavadas, T., "Virtual prototyping of assembly components using process modelling", Journal of Manufacturing Systems, 22 (1): 16, 2003.

[3] Ping, C.S., Keung, C.N.Y., Ramanathan, M., "Integrated team design process: successful stories of Hong Kong MTR corporation projects", Procedia Engineering, Hong Kong, Vol. 14, pp. 1190-1196, 2011. 
[4] Barbosa, G.F., Carvalho, J., "Guideline tool based on design for manufacturing and assembly (DFMA) methodology for application on design and manufacturing of aircrafts", Journal of the Barzilian Society of Mechanical Sciences and Engineering, Vol. 36 (3), pp. 605614, 2014.

[5] Devid A. Guerra- Zubiaga, Edgar Rios, Robert Parkin, Mike Jackson, Mileta Tomovic, Ricardo Ramirez-Mendoza, "Mechatronics Design Methodology Applied at Manufacturing Companies", International Journal of Manufacturing Technology and Management, Vol. 19 (34) pp. $191-210,2010$.

[6] Iwata K., Onosato M., Teramoto K., Osaki S.A., "Modeling and Simulation Architecture for Virtual Manufacturing System", Annals CIRP, 44, pp. 399-402, 1995.

[7] Marinov V., "What Virtual Manufacturing is? Part I: Definition", bosphorus.eng.emu.edu.tr/vmarinov/VM/VMspace.htm, 2000.

[8] Chudoba, K, Wynn, E., Lu, M., Watwon-Manheim, M., "How virtual are we? Measuring virtually and understanding its impact in a global organization", Information Systems Journal, 15(4): 279-306, 2005.

[9] Grieves, M. "Product Lifecycle Management: Drviving next generation of the lean thinking", McGraw Hill, 2006.

[10] Barbosa, G.F., Carvalho, J., Filho, F.V.G., "A proper framework for design of aircraft production system based on lean manufacturing principles focusing to automated processes", The International Journal of Advanced Manufacturing Technology, Vol. 72 (9), pp. 1257-1273, 2014.

[11] Ngoc Anh Vu, Abdulaziz Azamatov, Tun Lwin, Jae-Wo Lee., "Development of integrated rotorcraft design and virtual manufacturing framework", Aircraft Engineering and Aerospace Technology, Vol. 83, issue 3, pp. 171-185, 2011.

[12] Butterfild, J., Crosby, S., Curran, R., Price, M., Armstrong, C.G., Raghunathan, S., McAleenan, D. and Gibson, C., "Optimization of Aircraft Fuselage assembly Process using Digital Manufacturing", Journal of Computing and Information Science in Engineering, Vol 7(3), pp. 269-275, 2007.

[13] Saadoun M., Sandoval V., "Virtual Manufacturing and its implication, Virtual reality and prototyping", Laval, France, 1999.

[14] Chedmail P., Chablat D., Le Roy Ch., "A distributed Approach for Access and Visibility Task with a Manikin and a robot in a Virtual Reality Environment", IEEE Tranctions on Industrial Electronics, 2003.

[15] Dutta, D., Wolowics, J.P., "An Introduction to Product lifecycle Management (PLM)", ISPE, 2005.

[16] Ameri, F., Dutta, D., "Product lifecycle management: closing the knowledge loops" Computer Aided Design \& Applications, 2(5), pp. 577-590, 2005.

[17] CIMdata, inc., "Product Lifecycle Management", Empowering the future of business, 2003.

[18] Abramovici, M., Sieg, O.C., "Status and development trends of product lifecycle management systems", Proceedings of the IPPD 2002 Wroc-law, Poland, 2002.

[19] Elham, A., La Rocca, G., Van Tooren, M.J.L., "Development and implementation of advanced design-sensitive method for wing weight estimation", Aerospace Science and Technology, Vol. 29(1), pp. 100-113, 2013.

[20] Than Lin, Jae-Woo Lee, Tun Lwin, "Integrated approach for rotor blade manufacturing cost estimate", Aircraft Engineering and Aerospace Technology, Vol. 83(4), pp. 235-244, 2011.

[21] IBM, "Dassault aviation revolutionizes aircraft development with the Virtual Platform and PLM", 2004. 